\title{
RASSE DES NEUX, Recueil poétique (BnF, Manuscrit français 22565)
}

\section{Maurizio Busca}

\section{(2) OpenEdition}

\section{Journals}

\section{Edizione digitale}

URL: https://journals.openedition.org/studifrancesi/31483

DOI: 10.4000/studifrancesi.31483

ISSN: 2421-5856

\section{Editore}

Rosenberg \& Sellier

\section{Edizione cartacea}

Data di pubblicazione: 1 août 2020

Paginazione: 387

ISSN: 0039-2944

\section{Notizia bibliografica digitale}

Maurizio Busca, «RASSE des neux, Recueil poétique (BnF, Manuscrit français 22565)», Studi Francesi

[Online], 191 (LXIV | II) | 2020, online dal 01 septembre 2020, consultato il 18 septembre 2021. URL: http://journals.openedition.org/studifrancesi/31483; DOI: https://doi.org/10.4000/studifrancesi. 31483

Questo documento è stato generato automaticamente il 18 septembre 2021.

\section{(c) (i) ()}

Studi Francesi è distribuita con Licenza Creative Commons Attribuzione - Non commerciale - Non opere derivate 4.0 Internazionale. 


\title{
RASSE DES NEUX, Recueil poétique (BnF, Manuscrit français 22565)
}

\author{
Maurizio Busca
}

\section{NOTIZIA}

RASSE DES NEUX, Recueil poétique (BnF, Manuscrit français 22565), éd. G. schrenck, avec la collaboration de Ch. Nicolas, Paris, Classiques Garnier, 2019, «Textes de la Renaissance» $218,582 \mathrm{pp}$.

1 Medico chirurgo e bibliofilo erudito, figura complessa e ancora poco studiata del pieno Cinquecento francese, François Rasse des Neux ha raccolto per decenni centinaia di pasquils circolanti negli anni delle Guerre di religione, componendo sei voluminose raccolte manoscritte che, ad oggi, sono state edite soltanto in maniera molto frammentaria e spesso insoddisfacente. Con il presente volume Gilbert Schrenck propone non soltanto la prima edizione affidabile di una di queste sei compilazioni, ma anche il primo lavoro di sintesi sul compilatore stesso. Il suo intento è di rilevare come gli album di Rasse riflettano, oltre che eventi politici, sociali e religiosi dell'epoca, anche movimenti d'opinione che trovano nella pratica della scrittura pasquillaire e nella dimensione della polemica una forma privilegiata di espressione e diffusione.

2 La corposa introduzione traccia nelle prime pagine (pp. 9-19) la storia della circolazione dei sei manoscritti di Rasse, segnalando puntualmente le varie trascrizioni ed edizioni parziali che si sono succedute dal Seicento ad oggi. Si passa quindi alla ricognizione degli studi critici, nell'ambito della quale viene sottolineata l'importanza dei contributi di J. Veyrin-Forrer e di F. Rouget (oltre agli interventi di J. Pineaux, J.-Cl. Margolin, F. Charpentier et M. Greengrass) per la conoscenza di Rasse, della sua biblioteca e delle sue raccolte di pasquils. Nel capitolo successivo (pp. 20-41), fondato su un meticoloso lavoro di documentazione, si ricostruisce la composizione della famiglia del medico bibliofilo e si ripercorre la vita di quest'ultimo, mettendone in luce soprattutto alcuni aspetti: la carriera e l'impegno politico; le relazioni con colleghi, editori e amici; la 
dedizione alla pratica di compilazione; infine, la vastità degli interessi culturali, attestata dalla ricchezza della biblioteca composta da quasi trecento opere di carattere scientifico, filosofico, teologico, storico e geografico, oltre a testi letterari antichi e moderni, in versi e in prosa (pp. 41-77). Le pagine conclusive sono dedicate al testo edito (il Ms fr 22565, che l'editore considera come la più notevole delle sei raccolte per ragioni di varietà formale, tematica e cronologica) e al ruolo di Rasse quale passeur e autore di pasquils (pp. 78-109). Viene fornita la descrizione del manoscritto e ne viene presentato il contenuto, di cui Schrenck sottolinea la natura estremamente eterogenea: le 345 pièces raccolte, alcune delle quali provenienti da altre zone d'Europa, sono state composte in un arco temporale piuttosto ampio (i testi datati coprono gli anni 1540-1575) e, pur accomunate dall'elemento satirico (politico, religioso e di costume), sono caratterizzate da una varietà generica e da un'effervescenza verbale considerevoli. 